\title{
HER2 overexpression reverses the relative resistance of EGFR-mutant H1975 cell line to gefitinib
}

\author{
JING XU ${ }^{1,2}$, LI SHEN $^{1,2}$, BI-CHENG ZHANG ${ }^{1}$, WEN-HONG XU ${ }^{1,2}$, \\ SHU-QIN RUAN ${ }^{3}$, CHI PAN ${ }^{2}$ and QI-CHUN WEI ${ }^{1,2}$ \\ ${ }^{1}$ Department of Radiation Oncology, The Second Affiliated Hospital, Zhejiang University School of Medicine; \\ ${ }^{2}$ National Ministry of Education Key Laboratory of Cancer Prevention and Intervention, \\ Zhejiang University School of Medicine, Hangzhou, Zhejiang 310009; \\ ${ }^{3}$ Department of Oncology, Chongqing Zhongshan Hospital, Chongqing 400013, P.R. China
}

Received July 5, 2015; Accepted October 24, 2016

DOI: $10.3892 / \mathrm{ol} .2016 .5373$

\begin{abstract}
Gefitinib is an epidermal growth factor receptor tyrosine kinase inhibitor (EGFR TKI) that has been demonstrated to be clinically useful for the treatment of patients with non-small cell lung cancer (NSCLC). However, 50\% of patients do not respond to EGFR TKI treatment through the emergence of mutations, such as T790M. Therefore, it is important to determine which patients are eligible for treatment with gefitinib. As a preferred dimerization partner for EGFR, the role of EGFR 2 (HER2) in mediating sensitivity to gefitinib is poorly understood. In the present study, full-length human HER 2 cDNA was introduced to the NSCLC cell lines H1975 and H1299, which have a low endogenous expression level of HER2. In addition, it was observed in the present study that the H1975 cell line harbored the L858R and T790M mutations in the EGFR kinase domain. Western blot analysis and MTT assay were used to evaluate the TKI sensitivity of HER2 expression status, and the activation of HER3 and HER2 downstream effectors. The results indicated that the sensitivity of H1975 cells to gefitinib was restored by the overexpression of HER2, which stimulated HER2-driven signaling cascades accompanied by the activation of protein kinase B. By contrast, ectopic HER2 overexpression in H1299 cells did not significantly alter the sensitivity to gefitinib treatment. In conclusion, the current study results suggested that the relatively resistance of the H1975 cell line to gefitinib could be reversed by the overexpression of HER2. Therefore, the expression of HER2 could also be considered when evaluate the patients' potential
\end{abstract}

Correspondence to: $\mathrm{Dr} \mathrm{Li}$ Shen, Department of Radiation Oncology, The Second Affiliated Hospital, Zhejiang University School of Medicine, 88 Jiefang Road, Hangzhou, Zhejiang 310009, P.R. China

E-mail: shenlizju@163.com

Key words: human epidermal growth factor receptor 2, lung cancer, gefitinib, mutation, tyrosine kinase inhibitor response to gefitinib, particularly in the subgroup of lung cancer patients who harbor an EGFR mutation.

\section{Introduction}

The epidermal growth factor receptor (EGFR) family consists of four homologous members, including: EGFR, also named ErbB1 or human EGRF 1 (HER1); ErbB2 or HER2/Neu; ErbB3/HER3; and ErbB4/HER4 (1). These receptors contain an extracellular ligand-binding site, a hydrophobic membrane-spanning region and an intracellular tyrosine kinase-containing domain (2). Ligand binding promotes EGFR dimerization and activates intrinsic protein kinase activity, initiating cascades of cytoplasmic signal transduction pathways, including the mitogen-activated protein kinase/extracellular signal-regulated kinase (MAPK/Erk) and the phosphoinositide-3-kinase/protein kinase B (PI3K/Akt) signaling pathways. Activation of these pathways has been demonstrated to regulate fundamental cellular processes, including cell proliferation and survival (3).

Lung cancer is one of the most frequently diagnosed types of cancer among males and females in China and in Western countries, and it remains the leading cause of cancer mortality in the USA, with estimated 222,520 new cases and 157,300 mortalities in 2010 (4). Non-small cell lung cancer (NSCLC) accounts for $85 \%$ of all lung cancer cases (5). Chemotherapy provides symptomatic control and a moderate improvement in survival; however, prognosis is relatively poor, with a median time for progression ranging between 3 and 5 months (6). Targeted therapies, such as those based on the EGFR family, appear to provide the most promising solution for lung cancer patients in the future.

The EGFR family is implicated in the pathogenesis of numerous malignant diseases, and its members are commonly overexpressed in NSCLC, making them an attractive target for lung cancer therapy. One of the representative agents in molecular targeting is the tyrosine kinase inhibitor (TKI), an oral nonpeptide anilinoquinazoline compound that competes with ATP binding and blocks EGFR tyrosine kinases (7). Two large randomized phase II studies (IDEAL1 and IDEAL2) in pretreated patients with advanced NSCLC have demonstrated 
clinically significant benefits of gefitinib, an EGFR TKI, in symptom improvement and tumor regression, as well as tolerable toxicity mostly associated with skin rash and diarrhea $(8,9)$. However, the emergence of mutations, such as T790M in the kinase domain of EGFR, which is observed in $\sim 50 \%$ of patients with acquired resistance, has become a clinical concern (10).

Determining the prognosis of NSCLC patients is challenging, thus identifying novel biological markers that can predict the therapeutic outcome of gefitinib is urgent. Mutations of the K-ras and EGFR have been shown to correlate with sensitivity to EGFR TKIs in NSCLC $(11,12)$. An intensive crosstalk exists among the EGFR family members. However, in terms of HER2, there are conflicting results regarding whether HER2 expression is correlated with the susceptibility of tumor cells to gefitinib. Cappuzzo et al demonstrated that increased HER2 gene copy number was significantly associated with gefitinib sensitivity in a cohort of EGFR-positive NSCLC patients (13). By contrast, HER2 amplification was regarded as an unrecognized mechanism of acquired resistance that occurs in a subset of tumors lacking the EGFR T790M mutation (14). Therefore, the impact of HER2 dysregulation on gefitinib sensitivity in tumor cells harboring the EGFR T790M mutation remains unclear.

The present study examined two human NSCLC cell lines, H1975 and H1299, which harbor a low endogenous level of HER2 and are resistant to gefitinib treatment. Mutational analysis revealed the presence of the L858R and T790M EGFR mutations in the H1975 cell line, whereas no mutations were detected in the EGFR TK domain and the K-ras gene in H1299 cells. In addition, the study investigated whether an increase in HER2 expression was able to alter cell sensitivity to gefitinib. To explore the underlying mechanism, the phosphorylation of HER 3 and the activation of HER2 downstream effectors, as observed by the phosphorylation of Akt and Erk1/2, were also examined.

\section{Materials and methods}

Materials. Gefitinib was provided by AstraZeneca (Macclesfield, UK). Antibodies against EGFR (ab52894; 1:1,000), HER2 (ab134182; 1:10,000), HER3 (ab32121; 1:1,000), Erk1/2 (ab196883; 1:1,000), Akt (ab32505; 1:5,000); phospho-Akt (Ser473) (ab81283; 1:5,000), phospho-HER3 (ab5470; 1:500) and $\beta$-actin (ab6276; 1:5,000) were obtained from Epitomics (Abcam, Cambridge, MA, USA). Anti-phospho-Erk1/2 (Thr202/Tyr204) (9101S; 1:1,000) was purchased from Cell Signaling Technology, Inc. (Danvers, MA, USA).

Cell culture and stable transfections. The cell lines H1975 and H1299 (Cell Bank of the Chinese Academy of Sciences, Shanghai, China) were cultured in RPMI-1640 medium supplemented with $10 \%$ fetal bovine serum (FBS; both from Gibco; Thermo Fisher Scientific, Inc., Waltham, MA, USA). HER2-transfected H1975 and H1299 cells were cultured in RPMI-1640 medium supplemented with 10\% FBS and G418 (250 and $200 \mu \mathrm{g} / \mathrm{ml}$, respectively). Cells were maintained in a humidified chamber at $37^{\circ} \mathrm{C}$ with $5 \%$ carbon dioxide.

A HER2 expression plasmid pcDNA3.1 was provided by Dr Yikang Shi (National Glycoengineering Research
Center, Shandong University, Jinan, China). The full-length human HER2 cDNA (GenBank no., M11730.1) was sequence confirmed, digested by restriction enzymes NheI and XhoI, and ligated into the expression vector pIRES2-EGFP (Clontech; Takara Bio, Inc., Mountain View, CA, USA). Stable transfections were performed using Lipofectamine 2000 reagent (Invitrogen; Thermo Fisher Scientific, Inc.). Subsequent to transfection, the vector-transfected and HER2-expressing H1975 and H1299 cell lines were exposed for 2-3 weeks in G418-containing medium (with 250 and $200 \mu \mathrm{g} / \mathrm{ml} \mathrm{G} 418$, respectively). The pIRES2-EGFP-HER2 transfectant, mock vector transfectant and the parent cells of the two cell lines were named as follows: H1975/HER2, H1975/mock and H1975/parent, respectively; H1299/HER2, H1299/mock and H1299/parent, respectively. HER2 protein expression was determined by western blot analysis.

MTT assay. Following hemocytometer counting, the cells were plated in triplicate at a density of 3,500 cells/well in 96-well plates. The cells were allowed to attach overnight on the dishes and were treated the following day with serially diluted concentrations of gefitinib. The concentrations of gefitinib were serially diluted $(40,20,10,5,2.5$ and $1.25 \mu \mathrm{M})$. Following 2 days of incubation with gefitinib, $20 \mu \mathrm{l}$ of $5 \mathrm{mg} / \mathrm{ml}$ MTT solution [also known as 3-(4,5-dimethylthiazol-2-yl)-2,5-diphenyltetrazolium bromide; Sigma-Aldrich, Oakville, ON, USA] in phosphate-buffered saline (PBS) was added to each well and incubated under standard cell culture conditions for $4 \mathrm{~h}$. At the end of the assay, the crystals were dissolved in $150 \mu \mathrm{l}$ dimethyl sulfoxide (Sangon Biotech Co., Ltd., Shanghai, China) and vibrated slightly for $10 \mathrm{~min}$. The optical density (OD) of each well was measured with an ELISA plate reader at $570 \mathrm{~nm}$, and the half maximal inhibitory concentration $\left(\mathrm{IC}_{50}\right)$ was determined. The results are presented as the mean \pm standard deviation of triplicate experiments and are shown as a percentage of untreated control cells.

Molecular analyses of the status of EGFR and K-ras genes. The mutation status of EGFR (exons 18-21) and K-ras (exons 12 and 13) were analyzed by polymerase chain reaction (PCR) amplification of genomic DNA and direct sequencing. Genomic DNA was extracted from the H1975 and H1299 cell lines using a DNA extraction kit (catalog no. \#D0063; Beyotime Institute of Biotechnology, Hangzhou, China), according to the manufacturer's protocol. Amplification of EGFR and K-ras was performed using the primers listed in Table I. PCR was performed in a total volume of $50 \mu 1$, in a mixture containing $5 \mu \mathrm{l}$ Takara 10X Ex Taq buffer $\left(\mathrm{Mg}^{2+}\right.$ Plus), $4 \mu \mathrm{l}$ Takara dNTP mixture (2.5 mM each), $0.25 \mu \mathrm{l}$ Takara Ex Taq DNA polymerase (1.25 U), $0.5 \mu \mathrm{g}$ DNA, and $1 \mu \mathrm{l}$ of each primer pair for EGFR and K-ras. Initial denaturation was conducted at $95^{\circ} \mathrm{C}$ for $2 \mathrm{~min}$, followed by 30 cycles of PCR program, which consisted of denaturation at $94^{\circ} \mathrm{C}$ for $30 \mathrm{sec}$, specific annealing temperature $\left(50-61^{\circ} \mathrm{C}\right)$ for $30 \mathrm{sec}$, and extension at $72^{\circ} \mathrm{C}$ for $1 \mathrm{~min}$. A final extension step was performed at $72^{\circ} \mathrm{C}$ for $10 \mathrm{~min}$. The samples were subjected to sequence analysis using a cycle sequencing kit (Applied Biosystems; Thermo Fisher Scientific, Inc.) and the 3730XL DNA Analyzer (Applied Biosystems; Thermo Fisher Scientific, Inc.). 
Table I. Primers used for amplification of genomic DNA sequences of EGFR and K-ras exons.

\begin{tabular}{lll}
\hline Gene & \multicolumn{1}{c}{ Forward } & Reverse \\
\hline K-ras & & \\
Exon 2 & 5'-CTTAAGCGTCGATGGAGGAG-3' & 5'-CCCTGACATACTCCCAAGGA-3' \\
Exon 3 & 5'-TGGGTATGTGGTAGCATCTCA-3' & 5'-AATCCCAGCACCACCACTAC-3' \\
EGFR tyrosine kinase & & \\
Exon 18 & 5'-CAAATGAGCTGGCAAGTGCCGTGT-3' & 5'-GAGTTTCCCAAACACTCAGTGAAA-3' \\
Exon 19 & 5'-GCAATATCAGCCTTAGGTGCGGCTC-3' & 5'-CATAGAAAGTGAACATTTAGGATGTG-3' \\
Exon 20 & 5'-ACTTCACAGCCCTGCGTAAAC-3' & 5'-ATGGGACAGGCACTGATTTGT-3' \\
Exon 21 & 5'-CTAACGTTCGCCAGCCATAAGTCC-3' & 5'-GCTGCGAGCTCACCCAGAATGTCTGG-3'
\end{tabular}

EGFR, epidermal growth factor receptor.

Table II. Characteristics of non-small cell lung cancer cell lines.

\begin{tabular}{lcc}
\hline Cell line & EGFR status & K-ras status \\
\hline H1975 & L858R/T790M & Wild type \\
H1299 & Wild type & Wild type \\
\hline
\end{tabular}

EGFR, epidermal growth factor receptor.

Western blot analysis. The monolayer culture cells were maintained on $100 \mathrm{~mm}$ dishes in medium supplemented with $10 \%$ FBS. Cells were exposed to gefitinib at increasing concentrations $(0,1$ and $10 \mu \mathrm{m})$ for 1 or $24 \mathrm{~h}$ at $37^{\circ} \mathrm{C}$. Subsequently, the cells were rinsed with ice-cold PBS and lysed in mammalian protein extraction reagent (Pierce; Thermo Fisher Scientific, Inc.) containing phosphatase inhibitor cocktail (Pierce; Thermo Fisher Scientific, Inc.) for 10-20 min on ice. Protein concentration was determined using a BCA reagent (Pierce; Thermo Fisher Scientific, Inc.). Equal amounts of each protein sample $(30 \mu \mathrm{g})$ were separated by electrophoresis on 8-12\% SDS-polyacrylamide gels and transferred to polyvinylidene difluoride Hybond-P membranes (GE Healthcare, Chicago, IL, USA). Following transfer, the blots were incubated with the blocking solution and probed with antibodies against EGFR, HER2, HER3, Erk1/2, Akt, phospho-Akt (Ser473), phospho-Erk1/2 (Thr202/Tyr204), phospho-HER3 and $\beta$-actin, followed by successive washes with Tris-buffered saline. An enhanced chemiluminescence kit (catalog no. KGP1121-KGP1126; KeyGen Biotech Co., Ltd., Nanjing, China) was used for detection. All experiments were performed in duplicate and provided similar results.

\section{Results}

Sensitivity of lung cancer cell lines to gefitinib. To determine the sensitivity of H1975 and H1299 cells to gefitinib, the cell viability upon treatment with different concentrations of gefitinib was examined by MTT assay (Fig. 1A). IC $_{50}$ values were calculated using GraphPad Prism software version 3.0 (GraphPad Software, Inc., La Jolla, CA, USA). The two cell lines were observed to be resistant of gefitinib, with $\mathrm{IC}_{50}$ values
A H1975 H1299

EGFR
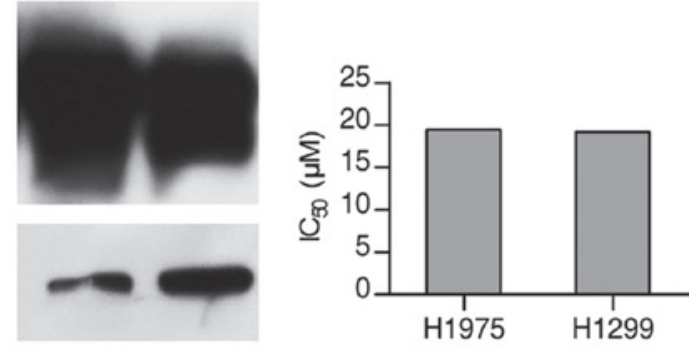

B H1975 H1299

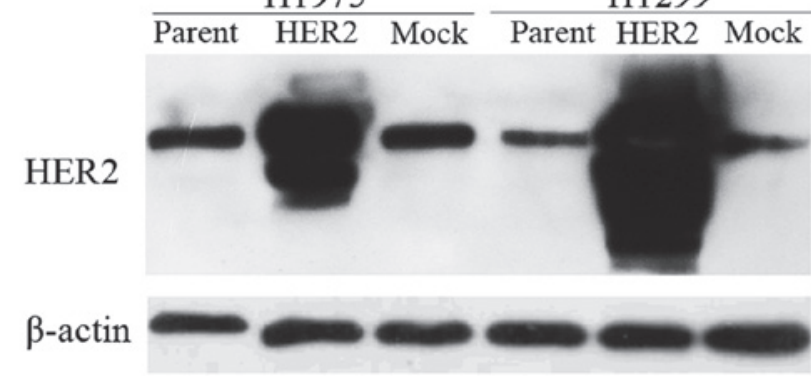

Figure 1. Correlation of gefitinib sensitivity with expression levels of EGFR and HER2. (A) Cellular protein levels of EGFR and HER2 were determined by western blotting using $30 \mu \mathrm{g}$ total cell lysates of each cell type. MTT assays were performed for cells incubated for $48 \mathrm{~h}$ with various concentrations of gefitinib. All experiments were performed in duplicate and averaged. (B) Protein expression of HER2 in H1975 and H1299 cell lines, and in their HER2 transfectants. Comparison of HER2 protein expression status in the H1975 and H1299 cells transfected with HER2 or mock vector. EGFR, epidermal growth factor receptor; HER, human EGRF.

of $\sim 20 \mu \mathrm{m}$. The results of western blot analysis verified the comparable expression levels of EGFR and HER2 in these two cell lines (Fig. 1A).

Molecular analysis. Mutations in EGFR and K-ras have been identified in lung adenocarcinomas and these mutations are correlated with sensitivity of gefitinib (15). Since resistance to gefitinib in the two cell lines investigated in the present study was observed, the EGFR (exons 18-21) and K-ras (exons 12 and 13) mutation status was examined by direct sequencing. Mutational analysis revealed the presence of the L858R and T790M EGFR mutation in the H1975 cell line. However, no 
A
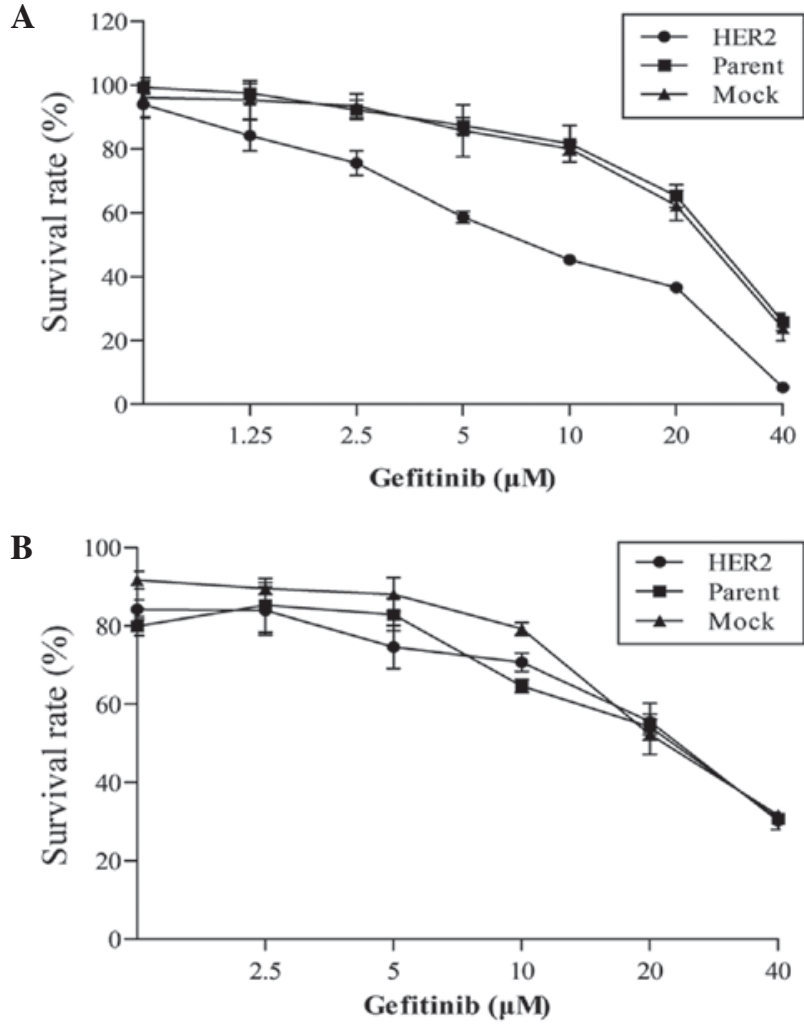

Figure 2. Overexpression of the HER2 enhances the sensitivity of the H1975 cell line to gefitinib. Dose-response curves of (A) H1975 and (B) H1299 cells transfected with HER2 or mock vector following gefitinib exposure. Sensitivity to gefitinib was determined by MTT assay in the absence or presence of an increasing gradient of gefitinib $(2.5,5,10,20$ and $40 \mu \mathrm{M})$. Results are presented as the mean \pm standard deviation of triplicate experiments and are shown as a percentage of untreated control cells. HER2, human epidermal growth factor receptor 2 .

mutations were detected in the EGFR TK domain and the K-ras gene in H1299 cells (Table II).

Overexpression of the HER2 enhances the sensitivity of the H1975 cell line to gefitinib. The present study next investigated whether increased expression of HER2 was able to alter the sensitivity of cells to gefitinib. Therefore, HER2 expression plasmids were introduced into the two lung cancer cell lines. The HER2 stable transfectants (H1975/HER2 and H1299/HER2) exhibited higher HER2 protein expression levels compared with the corresponding parental cell lines or with the mock transfectants (Fig. 1B). An MTT assay was then performed in the presence of increasing doses of gefitinib. Upon HER2 overexpression, H1975/HER2 cells displayed a 3-4-fold higher sensitivity to gefitinib $\left(\mathrm{IC}_{50}\right.$ at $6.19 \mu \mathrm{m}$ compared with $\sim 20 \mu \mathrm{m}$ in mock or parental cells). On the contrary, HER2 overexpression in H1299 cells did not significantly affect gefitinib sensitivity (Fig. 2).

Effect of gefitinib on phospho-Akt (Ser473), phospho-Erkl/2 (Thr202/Tyr204) and phospho-HER3. Fig. 3A and B shows the inhibitory dose kinetics of gefitinib for phospho-Akt and phospho-Erk in H1975 and H1299 cells, with the phosphorylation level in untreated cells normalized to $100 \%$. The results of the present study identified that gefitinib treatment effectively
A

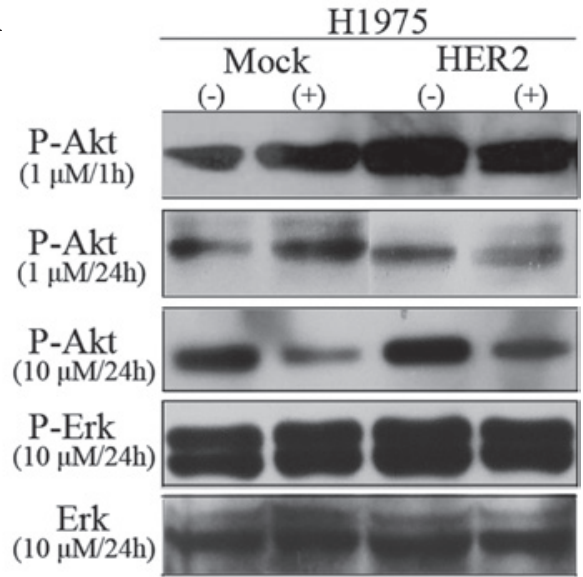

B

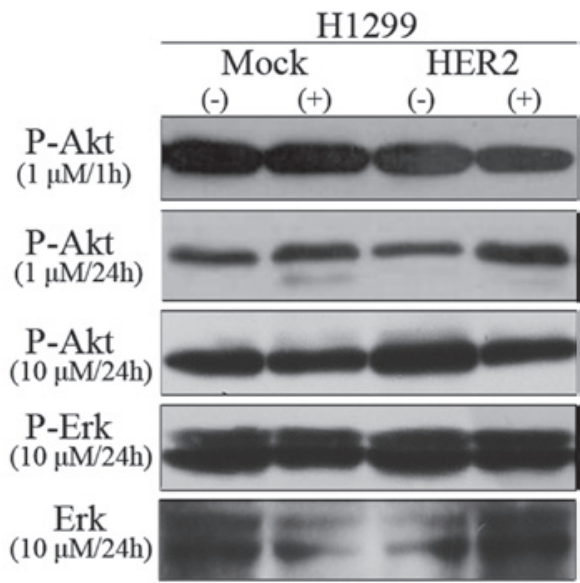

C

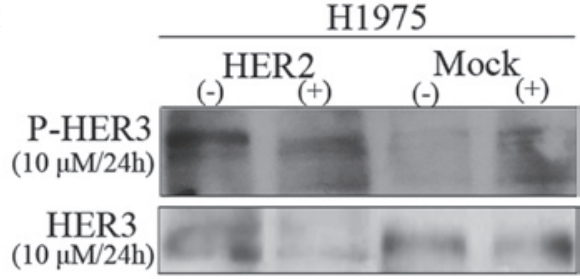

Figure 3. Effect of gefitinib on P-Akt (Ser473), P-Erk1/2 (Thr202/Tyr204) and P-HER3 levels. (A) Dose-dependent and (B) time-dependent inhibition of Akt and Erk1/2 phosphorylation in H1975 and H1299 cell lines are shown by western blot analysis. Cells were treated for 1 or $24 \mathrm{~h}$ with the indicated concentrations of gefitinib. Two independent experiments provided similar results. (C) Effect of gefitinib on P-HER3 in H1975 cell lines in the presence of $10 \%$ serum. P, phosphorylated; Akt, protein kinase B; Erk, extracellular signal-regulated kinase; HER, human epidermal growth factor receptor.

decreased Akt phosphorylation in a dose- and time-dependent manner in EGFR-mutant H1975 cell line. In addition, gefitinib inhibited Akt phosphorylation equally in H1299/HER2 or H1299/mock cells. By contrast, Erk1/2 phosphorylation was not altered by gefitinib treatment up to $10 \mu \mathrm{m}$ in both $\mathrm{H} 1975$ and $\mathrm{H} 1299$ cells.

The effect of gefitinib on phospho-HER3 in H1975 cell lines in the presence of 10\% FBS was also assayed (Fig. 3C). Phospho-HER3 was increased by 2 -fold in H1975/HER2 in the absence of gefitinib treatment. However, treatment with $10 \mu \mathrm{m}$ gefitinib for $24 \mathrm{~h}$ evidently reduced HER3 phosphorylation. In conclusion, HER 2 overexpression was able to sensitize H1975 cells to gefitinib, which stimulated 
HER2-driven signaling cascades accompanied by the activation of Akt.

\section{Discussion}

EGFR and/or HER2 are expressed at high levels in a wide spectrum of malignancies, including lung cancer, breast cancer, esophageal carcinoma, ovary cancer and gliomas $(16,17)$. Their overexpression usually correlates with a more aggressive disease course and poor clinical prognosis (18). Gefitinib, a tyrosine kinase inhibitor, can compete with ATP, as well as inhibit EGFR and HER2 kinase activities in vitro with an $\mathrm{IC}_{50}$ of 27-33 nmol/1 and $>3.7 \mu \mathrm{mol} / 1$, respectively (19). Although gefitinib exerts its antitumor activity selectively through the inhibition of EGFR, recent reports have demonstrated that the antitumor activity of gefitinib does not directly depend on EGFR $(12,20)$. In addition, no apparent difference in sensitivity to gefitinib was observed between the human lung cancer line LK2 and its EGFR derivatives (LK2/EGFR) (21). On the contrary, according to several retrospective studies of patients with advanced NSCLC, increased HER2 gene copy number was statistically significantly associated with response to gefitinib treatment $(13,22)$. Furthermore, the impact of HER2 expression level on gefitinib sensitivity has also been reported in a series of human breast cancer and epithelial cell lines $(19,23)$. Taken together, these results suggested that HER2 levels appeared to be correlated with the susceptibility of tumor cells to gefitinib.

However, a study by Takezawa et al indicated that HER2 amplification is a mechanism of acquired resistance to EGFR TKI in EGFR-mutant tumor cell lines that lack the second-site EGFR T790M mutation (14). The impact of HER2 dysregulation on gefitinib sensitivity in tumor cells harboring the T790M mutation remains unclear. In the present study, mutational analysis revealed the presence of the $\mathrm{L} 858 \mathrm{R}(\mathrm{T} \rightarrow \mathrm{G}$ mutation in exon 21) and T790M (C $\rightarrow$ T mutation in exon 20) EGFR mutations in the $\mathrm{H} 1975$ cell line, whereas no mutation was detected in both the EGFR TK domain and the K-ras gene in H1299 cells. The H1975 and H1299 cell lines were selected as cell models to examine whether an increase in HER2 expression level was able to alter the cell sensitivity to gefitinib in cells harboring the EGFR T790M mutation. The NSCLC cell line H1975 with HER2 overexpression presented increased sensitivity to gefitinib with an $\mathrm{IC}_{50}$ of $\sim 6 \mu \mathrm{m}$, compared with the parental cell line that had an $\mathrm{IC}_{50}$ of $20 \mu \mathrm{m}$. The discrepancies between these values and the maximum plasma concentration of gefitinib observed in patients $(\sim 1 \mu \mathrm{m})$ may be due to the different exposure time to gefitinib (24). The results of the present study strongly suggest that overexpression of HER2 may overcome T790M-mediated resistance. Notably, the relatively resistance of lung cancer cell line H1975 to gefitinib can be reversed by the overexpression of HER2. Therefore, the expression of HER2 may also be employed as a prognostic marker for lung cancer patients, particularly those harboring the T790M mutation in the kinase domain of EGFR.

HER 2 mutations within the tyrosine kinase domain are also considered to be associated with responsiveness of EGFR-TKIs in NSCLC and squamous cell carcinoma of the head and neck $(25,26)$. Prospective studies are required to confirm the role of HER2 in NSCLC and other tumor types as a prognostic marker for tumor responsiveness, in addition to mutations of the EGFR and K-ras.

It has been suggested that breast cancer cells with HER2 amplification were selectively dependent on Akt signaling and downregulation of Akt activity was a marker of the antitumor effect of gefitinib (23). In a study by Noro et al, cancer cell lines showing sensitivity to gefitinib also exhibited greater phospho-Akt levels in a panel of lung cancer cell lines (24). Data presented in the current study indicated that overexpression of HER2 in H1975 cells resulted in a marked inhibitory effect of gefitinib on Akt phosphorylation, but not on phospho-Erk1/2. Akt activity was demonstrated to promote resistance to chemotherapy and radiotherapy (27). This may provide an explanation for the combination of gefitinib with chemotherapy or radiotherapy as an effective strategy in phospho-Akt positive patients who are refractory to standard chemotherapy regimens (28). Noro et al also assumed that phosphorylation of Akt may be just a hallmark of sensing activation of other upstream molecules, such as HER2 (24). Therefore, phospho-Akt is a potential surrogate marker of the response to gefitinib, and precise assessment of clinical markers of Akt activation may help for efficient prognosis of gefitinib treatment.

The data of the current study revealed that a significant reduction in the levels of activation of Akt was required for gefitinib to induce cell death in the EGFR-mutant H1975 cell line. PI3K docking sites are absent on EGFR or HER2, however, docking sites for PI3K are highly prevalent on HER3 (29). It is noteworthy that HER2 is an orphan receptor for which no ligand has yet been identified, while the kinase activity of HER3 is defective (30). In this regard, EGFR and HER2 are not able to directly activate the PI3K/Akt pathway (20). In these tumors, activation of the PI3K/Akt pathway occurs through the transphosphorylation of HER3. Furthermore, HER 2 has been identified as the preferred binding partner of the other ErbB receptors (31). Thus, HER2 and HER3 can form heterodimeric complexes and act in a complementary manner, and the HER2/HER3 heterodimer is considered the most transforming and mitogenic receptor complex (32). Treatment with gefitinib can most significantly reduce the activity of the HER2/HER3 heterodimer and block the downstream signaling (20). In the present study, it was observed that phospho-HER3 was 2-fold higher in H1975/HER2 compared with that in the H1975/mock cells in the absence of drug. Furthermore, HER2 overexpression leads to more HER2 heterodimers, which increase their ligand binding affinity and result in more prolonged signals (33). These findings can thus account for the increase of HER2/HER3 heterodimer and HER2/HER2 homodimer levels in the HER2-overexpressing H1975 cell line. Therefore, gefitinib may downregulate the phospho-Akt more effectively in H1975/HER2 cells due to an increased number of available target sites. Chandarlapaty et al reported that PI3K/Akt inhibitors caused a feedback activation of receptor tyrosine kinase signaling, and simultaneous inhibition of Akt and HER kinase activity is more effective compared with single treatment (34). Hence, combined inhibition of Akt and EGFR family members may warrant further evaluation in clinical trials of NSCLC patients.

Restoration of p53 to p53-defective H1299 cells can enhance the sensitivity to gefitinib (35). In the present 
study, the resistant of H1299 cells to gefitinib could not be reversed by the ectopic overexpression of HER2. The present study observations were consistent with the hypothesis of Strobel et al (36) that an intact apoptotic pathway was necessary for chemotherapy-induced cytotoxicity. Furthermore, the lack of p53 gene affected the ability of a cell to undergo apoptosis and finally led to the development of chemotherapy resistance (36). Thus, the hypothesis that HER2 overexpression per se is sufficient to determine sensitivity to gefitinib may be over-simplistic.

The objective response rate of gefitinib was $\sim 15 \%$ when administered to lung cancer patients (37). However, the underlying mechanism of different drug sensitivity to gefitinib is not fully understood. In the present study, stable lung cancer cell lines of H1975 and H1299 overexpressing HER2 have been established. The data indicated that the sensitivity of H1975 cells to gefitinib could be restored by overexpression of HER2, which stimulated HER2-driven signaling cascades, accompanied by Akt activation. By contrast, ectopic HER2 overexpression in H1299 cells did not significantly alter the sensitivity to gefitinib. The present study demonstrated that a more comprehensive analysis is required to maximize the clinical benefits of gefitinib. Future studies should include potential clinical markers, such as p53, HER2, EGFR, the phosphorylation state of HER3 and Akt, along with other molecules that are associated with gefitinib sensitivity.

\section{Acknowledgements}

The present study was supported by a grant from the National Natural Science Foundation of China (grant no. 81201811).

\section{References}

1. Jorissen RN, Walker F, Pouliot N, Garrett TP, Ward CW and Burgess AW: Epidermal growth factor receptor: Mechanisms of activation and signalling. Exp Cell Res 284: 31-53, 2003.

2. Hynes NE and Lane HA: ERBB receptors and cancer: The complexity of targeted inhibitors. Nat Rev Cancer 5: 341-354, 2005.

3. Arora A and Scholar EM: Role of tyrosine kinase inhibitors in cancer therapy. J Pharmacol Exp Ther 315: 971-979, 2005.

4. Jemal A, Siegel R, Xu J and Ward E: Cancer statistics, 2010. CA Cancer J Clin 60: 277-300, 2010

5. Xue C, Hu Z, Jiang W, Zhao Y, Xu F, Huang Y, Zhao H, Wu J, Zhang Y, Zhao L, et al: National survey of the medical treatment status for non-small cell lung cancer (NSCLC) in China. Lung Cancer 77: 371-375, 2012

6. Shepherd FA, Rodrigues Pereira J, Ciuleanu T, Tan EH, Hirsh V, Thongprasert S, Campos D, Maoleekoonpiroj S, Smylie M, Martins R, et al: Erlotinib in previously treated non-small-cell lung cancer. N Engl J Med 353: 123-132, 2005.

7. Anido J, Matar P, Albanell J, Guzmán M, Rojo F, Arribas J, Averbuch S and Baselga J: ZD1839, a specific epidermal growth factor receptor (EGFR) tyrosine kinase inhibitor, induces the formation of inactive EGFR/HER2 and EGFR/HER3 heterodimers and prevents heregulin signaling in HER2-overexpressing breast cancer cells. Clin Cancer Res 9: 1274-1283, 2003.

8. Fukuoka M, Yano S, Giaccone G, Tamura T, Nakagawa K, Douillard JY, Nishiwaki Y, Vansteenkiste J, Kudoh S, Rischin D, et al: Multi-institutional randomized phase II trial of gefitinib for previously treated patients with advanced non-small-cell lung cancer (The IDEAL 1 Trial) [corrected]. J Clin Oncol 21: 2237-2246, 2003.

9. Kris MG, Natale RB, Herbst RS, Lynch TJ Jr, Prager D, Belani CP, Schiller JH, Kelly K, Spiridonidis H, Sandler A, et al: Efficacy of gefitinib, an inhibitor of the epidermal growth factor receptor tyrosine kinase, in symptomatic patients with non-small cell lung cancer: A randomized trial. JAMA 290: 2149-2158, 2003.
10. Arcila ME, Oxnard GR, Nafa K, Riely GJ, Solomon SB, Zakowski MF, Kris MG, Pao W, Miller VA and Ladanyi M: Rebiopsy of lung cancer patients with acquired resistance to EGFR inhibitors and enhanced detection of the T790M mutation using a locked nucleic acid-based assay. Clin Cancer Res 17: 1169-1180, 2011.

11. Landi L, Tiseo M, Chiari R, Ricciardi S, Rossi E, Galetta D, Novello S, Milella M, D'Incecco A, Minuti G, et al: Activity of the EGFR-HER2 dual inhibitor afatinib in EGFR-mutant lung cancer patients with acquired resistance to reversible EGFR tyrosine kinase inhibitors. Clin Lung Cancer 15: 411-417.e4, 2014.

12. Han SW, Kim TY, Jeon YK, Hwang PG, Im SA, Lee KH, Kim JH, Kim DW, Heo DS, Kim NK, et al: Optimization of patient selection for gefitinib in non-small cell lung cancer by combined analysis of epidermal growth factor receptor mutation, K-ras mutation, and Akt phosphorylation. Clin Cancer Res 12: 2538-2544, 2006.

13. Cappuzzo F, Varella-Garcia M, Shigematsu H, Domenichini I, Bartolini S, Ceresoli GL, Rossi E, Ludovini V, Gregorc V, Toschi L, et al: Increased HER2 gene copy number is associated with response to gefitinib therapy in epidermal growth factor receptor-positive non-small-cell lung cancer patients. J Clin Oncol 23: 5007-5018, 2005.

14. Takezawa K, Pirazzoli V, Arcila ME, Nebhan CA, Song X, de Stanchina E, Ohashi K, Janjigian YY, Spitzler PJ, Melnick MA, et al: HER2 amplification: A potential mechanism of acquired resistance to EGFR inhibition in EGFR-mutant lung cancers that lack the second-site EGFRT790M mutation. Cancer Discov 2: 922-933, 2012.

15. Pao W, Wang TY, Riely GJ, Miller VA, Pan Q, Ladanyi M, Zakowski MF, Heelan RT, Kris MG and Varmus HE: KRAS mutations and primary resistance of lung adenocarcinomas to gefitinib or erlotinib. PLoS Med 2: e17, 2005.

16. Wei Q, Chen L, Sheng L, Nordgren H, Wester K and Carlsson J: EGFR, HER2 and HER 3 expression in esophageal primary tumours and corresponding metastases. Int J Oncol 31: 493-499, 2007.

17. Hirsch FR, Varella-Garcia M, Cappuzzo F, McCoy J, Bemis L, Xavier AC, Dziadziuszko R, Gumerlock P, Chansky K, West $\mathrm{H}$, et al: Combination of EGFR gene copy number and protein expression predicts outcome for advanced non-small-cell lung cancer patients treated with gefitinib. Ann Oncol 18: 752-760, 2007.

18. Mendelsohn J and Baselga J: The EGF receptor family as targets for cancer therapy. Oncogene 19: 6550-6565, 2000.

19. Moulder SL, Yakes FM, Muthuswamy SK, Bianco R, Simpson JF and Arteaga CL: Epidermal growth factor receptor (HER1) tyrosine kinase inhibitor ZD1839 (Iressa) inhibits HER2/neu (erbB2)-overexpressing breast cancer cells in vitro and in vivo. Cancer Res 61: 8887-8895, 2001.

20. Normanno N, Maiello MR and De Luca A: Epidermal growth factor receptor tyrosine kinase inhibitors (EGFR-TKIs): Simple drugs with a complex mechanism of action? J Cell Physiol 194: 13-19, 2003.

21. Ono M, Hirata A, Kometani T, Miyagawa M, Ueda S, Kinoshita H, Fujii T and Kuwano M: Sensitivity to gefitinib (Iressa, ZD1839) in non-small cell lung cancer cell lines correlates with dependence on the epidermal growth factor (EGF) receptor/extracellular signal-regulated kinase 1/2 and EGF receptor/Akt pathway for proliferation. Mol Cancer Ther 3: 465-472, 2004.

22. Soh J, Toyooka S, Ichihara S, Fujiwara Y, Hotta K, Suehisa H, Kobayashi N, Ichimura K, Aoe K, Aoe M, et al: Impact of HER2 and EGFR gene status on gefitinib-treated patients with nonsmall-cell lung cancer. Int J Cancer 121: 1162-1167, 2007.

23. Moasser MM, Basso A, Averbuch SD and Rosen N: The tyrosine kinase inhibitor ZD1839 ('Iressa') inhibits HER2-driven signaling and suppresses the growth of HER2-overexpressing tumor cells. Cancer Res 61: 7184-7188, 2001.

24. Noro R, Gemma A, Kosaihira S, Kokubo Y, Chen M, Seike M, Kataoka K, Matsuda K, Okano T, Minegishi Y, et al: Gefitinib (IRESSA) sensitive lung cancer cell lines show phosphorylation of Akt without ligand stimulation. BMC Cancer 6: 277, 2006.

25. Shigematsu H, Takahashi T, Nomura M, Majmudar K, Suzuki M, Lee H, Wistuba II, Fong KM, Toyooka S, Shimizu N, et al: Somatic mutations of the HER2 kinase domain in lung adenocarcinomas. Cancer Res 65: 1642-1646, 2005.

26. Cohen EE, Lingen MW, Martin LE, Harris PL, Brannigan BW, Haserlat SM, Okimoto RA, Sgroi DC, Dahiya S, Muir B, et al: Response of some head and neck cancers to epidermal growth factor receptor tyrosine kinase inhibitors may be linked to mutation of ERBB2 rather than EGFR. Clin Cancer Res 11: 8105-8108, 2005. 
27. Brognard J, Clark AS, Ni Y and Dennis PA: Akt/protein kinase $\mathrm{B}$ is constitutively active in non-small cell lung cancer cells and promotes cellular survival and resistance to chemotherapy and radiation. Cancer Res 61: 3986-3997, 2001.

28. Han SW, Hwang PG, Chung DH, Kim DW, Im SA, Kim YT, Kim TY, Heo DS, Bang YJ and Kim NK: Epidermal growth factor receptor (EGFR) downstream molecules as response predictive markers for gefitinib (Iressa, ZD1839) in chemotherapy-resistant non-small cell lung cancer. Int J Cancer 113: 109-115, 2005.

29. Lurje G and Lenz HJ: EGFR signaling and drug discovery. Oncology 77: 400-410, 2009.

30. Ricciardi GR, Russo A, Franchina T, Ferraro G, Zanghì M, Picone A, Scimone A and Adamo V: NSCLC and HER2: Between lights and shadows. J Thorac Oncol 9: 1750-1762, 2014.

31. Garrido-Castro AC and Felip E: HER2 driven non-small cell lung cancer (NSCLC): Potential therapeutic approaches. Transl Lung Cancer Res 2: 122-127, 2013.

32. Yarden $Y$ and Sliwkowski MX: Untangling the ErbB signalling network. Nat Rev Mol Cell Biol 2: 127-137, 2001.

33. Fuller SJ, Sivarajah K and Sugden PH: ErbB receptors, their ligands, and the consequences of their activation and inhibition in the myocardium. J Mol Cell Cardiol 44: 831-854, 2008.
34. Chandarlapaty S, Sawai A, Scaltriti M, Rodrik-Outmezguine V, Grbovic-Huezo O, Serra V, Majumder PK, Baselga J and Rosen N: AKT inhibition relieves feedback suppression of receptor tyrosine kinase expression and activity. Cancer Cell 19: 58-71, 2011.

35. Rho JK, Choi YJ, Ryoo BY, Na II, Yang SH, Kim CH and Lee JC: p53 enhances gefitinib-induced growth inhibition and apoptosis by regulation of Fas in non-small cell lung cancer. Cancer Res 67: 1163-1169, 2007.

36. Strobel T, Swanson L, Korsmeyer S and Cannistra SA: BAX enhances paclitaxel-induced apoptosis through a p53-independent pathway. Proc Natl Acad Sci USA 93: 14094-14099, 1996.

37. Dudek AZ, Kmak KL, Koopmeiners J and Keshtgarpour M: Skin rash and bronchoalveolar histology correlates with clinical benefit in patients treated with gefitinib as a therapy for previously treated advanced or metastatic non-small cell lung cancer. Lung Cancer 51: 89-96, 2006 